\title{
Perspectives on the role of $\mathrm{mTORC2}$ in B lymphocyte development, immunity and tumorigenesis
}

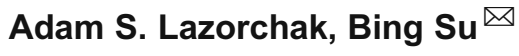 \\ Department of Immunobiology and the Vascular Biology and Therapeutic Program, Yale School of Medicine, New Haven, \\ CT 06519, USA \\ $\triangle$ Correspondence: bing.su@yale.edu
}

Received June 4, 2011 Accepted June 30, 2011

\section{ABSTRACT}

Mammalian target of rapamycin complex 2 (mTORC2) is a key downstream mediator of phosphoinositol-3kinase (PI3K) dependent growth factor signaling. In lymphocytes, mTORC2 has emerged as an important regulator of cell development, homeostasis and immune responses. However, our current understanding of mTORC2 functions and the molecular mechanisms regulating $m$ TORC2 signaling in $B$ and $T$ cells are still largely incomplete. Recent studies have begun to shed light on this important pathway. We have previously reported that mTORC2 mediates growth factor dependent phosphorylation of Akt and facilitates Akt dependent phosphorylation and inactivation of transcription factors FoxO1 and FoxO3a. We have recently explored the functions of $\mathrm{mTORC} 2$ in $B$ cells and show that mTORC2 plays a key role in regulating survival and immunoglobulin (Ig) gene recombination of bone marrow B cells through an Akt2-Fox01 dependent mechanism. Ig recombination is suppressed in proliferating $B$ cells to ensure that DNA double strand breaks are not generated in actively dividing cells. Our results raise the possibility that genetic or pharmacologic inhibition of mTORC2 may promote B cell tumor development as a result of inefficient suppression of Ig recombination in dividing $B$ cells. We also propose a novel strategy to treat cancers based on our recent discovery that $\mathrm{mTORC2}$ regulates Akt protein stability.

KEYWORDS mTOR, lymphocyte, B cell, cancer, mTORC2, FoxO, Akt, Sin1

\section{MAMMALIAN TORC2 REGULATES Akt ACTIVITY AND STABILITY}

Mammalian target of rapamycin (TOR) is a member of the phosphoinositide 3-kinase (PI3K)-related kinases (PIKK) subfamily of atypical protein kinases which regulates cellular growth, proliferation and survival in response to nutrients, energy and growth factor signals (Manning et al., 2002; Wullschleger et al., 2006). Mammalian TOR is incorporated into two functionally distinct multi-protein complexes called mammalian TOR complex 1 (mTORC1) and mTORC2 (Wullschleger et al., 2006; Guertin and Sabatini, 2009). Nutrients, energy and growth factor signals activate mTORC1, which in turn phosphorylates ribosomal protein S6 kinase (S6K) and translation initiation factor 4E-binding protein 1 (4E-BP1) to promote cellular protein synthesis and ribosome biogenesis (Harris and Lawrence, 2003; Gingras et al., 2004; Wullschleger et al., 2006; Guertin and Sabatini, 2009). The bacterially derived drug rapamycin acutely inhibits mTORC1 and is a potent immunosuppressant (Wullschleger et al., 2006; Guertin and Sabatini, 2009).

Mammalian TORC2 is resistant to acute inhibition by rapamycin. Interestingly, mTORC2 function may be blocked in cells that are chronically exposed to rapamycin, but the mechanism through which this inhibition of MTORC2 function occurs is currently unclear (Sarbassov et al., 2006; Zeng et al., 2007; Facchinetti et al., 2008). Mammalian TORC2 is composed of mTOR, Rictor, mitogen-activated protein kinase associated protein 1 (Mapkap1/Sin1), mLST8, Protein observed with Rictor (Protor/PRR5) and DEP domain containing $m T O R$ interacting protein (DEPTOR). Genetic deletion of Rictor, Sin1 or mLST8 in mammalian cells results in the disruption of the mTORC2 complex and loss of mTORC2 
function (Frias et al., 2006; Guertin et al., 2006; Jacinto et al., 2006). In yeast and mammalian cells, mTORC2 has been shown to regulate actin polymerization and cytoskeleton function (Wullschleger et al., 2006; Guertin and Sabatini, 2009). Recent studies have revealed that $m$ TORC2 regulates the activity and stability of the AGC family kinases Akt and conventional (c)PKC in both a PI3K-dependent and PI3Kindependent manner (Sarbassov et al., 2005; Frias et al., 2006; Jacinto et al., 2006; Hietakangas and Cohen, 2007; Facchinetti et al., 2008; Ikenoue et al., 2008).

Akt is a typical example of an AGC family kinase regulated by $\mathrm{mTORC2}$. Akt is activated in response to $\mathrm{PI} 3 \mathrm{~K}$ signaling by PDK1 dependent phosphorylation at the T-loop (Thr308 of Akt1) and mTORC2 dependent phosphorylation at the hydrophobic motif (HM) (Ser473 of Akt1). Phosphorylation at both the T-loop and HM fully activates Akt; however analysis of mTORC2 deficient Rictor and Sin 1 knockout cells revealed that T-loop phosphorylation may still occur normally in the absence of HM site phosphorylation (Guertin et al., 2006; Jacinto et al., 2006). Furthermore, Akt which lacks HM phosphorylation retains the ability to phosphorylate substrates such as GSK3 and TSC2, indicating that disruption of mTORC2 does not completely block Akt signaling (Jacinto et al., 2006). Interestingly, Akt HM phosphorylation is required for Akt dependent phosphorylation of the Forkhead transcription factors FoxO1 and FoxO3a (Jacinto et al., 2006). These findings led us to propose that $\mathrm{HM}$ phosphorylation regulates Akt substrate specificity. Currently, it is unclear how disruption of mTORC2 selectively impairs the phosphorylation of some but not all Akt substrates.

Phosphorylation of the HM site also regulates Akt protein stability in a growth factor dependent manner. We have recently shown that the degradation rate of Akt lacking $\mathrm{HM}$ phosphorylation is substantially lower than that of $\mathrm{HM}$ phosphorylated Akt (Wu et al., 2011). Akt HM phosphorylation promotes K48 polyubiquination of Akt and subsequent proteasomal degradation of the protein. Interestingly, Akt shows increased T-loop phosphorylation in mTORC2 deficient cells, suggesting that blocking HM phosphorylation impairs activation induced Akt degradation and results in the accumulation of activated Akt. Therefore, the phospho-HM directed Akt degradation may play an important role in limiting Akt signaling to prevent over activation of Akt and potential tumor development.

Mammalian TORC2 also regulates the stability of Akt and cPKC proteins in a growth factor independent manner. Studies in $\operatorname{Sin} 1$ and Rictor knockout cells revealed that phosphorylation of the highly conserved turn motif (TM) of Akt (Thr450 on Akt1) and cPKC is dependent on mTORC2 (Facchinetti et al., 2008; Ikenoue et al., 2008). Akt and cPKC TM phosphorylation is constitutive and occurs independently of growth factor or nutrient status. Phosphorylation of the TM site serves to promote proper folding of newly synthesized Akt or CPKC. In mTORC2 deficient cells, proper folding of Akt is rescued by association with the chaperone protein Hsp90 (Facchinetti et al., 2008). Mammalian TORC2 associates with actively translating ribosomes and phosphorylates the TM site of the nascent Akt polypeptide during translation (Oh et al., 2010). Consequently, Sin1 or Rictor knockout cells exhibit modestly reduced Akt and CPKC expression levels. However, inhibition of Hsp90 results in more rapid and almost complete abolishment of Akt and CPKC expression in mTORC2 deficient cells. In summary, mTORC2 regulates the folding of newly synthesized Akt and CPKC in a growth factor independent manner and the signaling and degradation of Akt in a growth factor independent manner.

\section{MAMMALIAN TORC2 REGULATES B LYMPHOCYTE DEVELOPMENT}

B cell development is a well defined process whose principle purpose is to facilitate the successful recombination and expression of a unique, non-autoreactive monoclonal antigen receptor on each mature $B$ cell. Each $B$ cell antigen receptor (BCR) is composed of two immunoglobulin heavy chain $(\mathrm{lgH})$ polypeptides plus two Ig light chain (IgL) polypeptides which are generated by somatic recombination of the lg genes. First, $\mathrm{lgH}$ gene recombination occurs in progenitor $B$ (pro-B) cells and, if successful, leads to the expression of the pre-BCR on the cell surface. Expression of the pre-BCR signals to the developing $B$ cell that a functional $\lg \mathrm{H}$ has been produced and permits differentiation into precursor B (pre-B) cells and subsequent IgL gene recombination (Llorian et al., 2007; Herzog et al., 2009). If a pre-B cell successfully rearranges an IgL allele then the expressed IgL polypeptide pairs with $\mathrm{IgH}$ and produces a functional BCR. Immature $\mathrm{BCR}^{+}\left(\mathrm{IgM}^{+}\right) \mathrm{B}$ cells then undergo selection to prevent cells expressing autoreactive antigen receptors from entering into the mature peripheral B cell pool. A cartoon illustrating the major stages of $B$ cell development is shown in Fig. 1.

We investigated the function of mTORC2 in $B$ cells by generating $\operatorname{Sin} 1^{-/-}$fetal liver hematopoietic stem cell (HSC) chimeric mice. Sin $1^{-/-}$HSCs are capable of reconstituting the hematopoietic system of lethally irradiated wild type host mice and restoring bone marrow B cell development. However, we found that $\operatorname{Sin} 1$ deficient progenitor $B$ cells gave rise to fewer $\mathrm{IgM}^{+}$immature $B$ cells than wild type controls. We investigated this partial block in bone marrow B cell development and found that $\operatorname{Sin} 1^{-1-}$ pro-B cells exhibited significantly higher expression of the interleukin 7 (IL-7) receptor than wild type pro-B cells. Mouse pro-B cells depend on IL-7 produced by the bone marrow stromal environment to maintain cell survival and suppress IgL gene recombination (Malin et al., 2010). Consistently, we found that $\operatorname{Sin} 1^{-/-}$pro-B exhibited increased IL-7 dependent cell survival when compared to wild type cells and that $\operatorname{Sin} 1^{-/-}$pro-B exhibited a delay in the development of $\operatorname{lgM}^{+}$cells compared to wild type cells when cultured with a low concentration of IL-7. These data indicate 

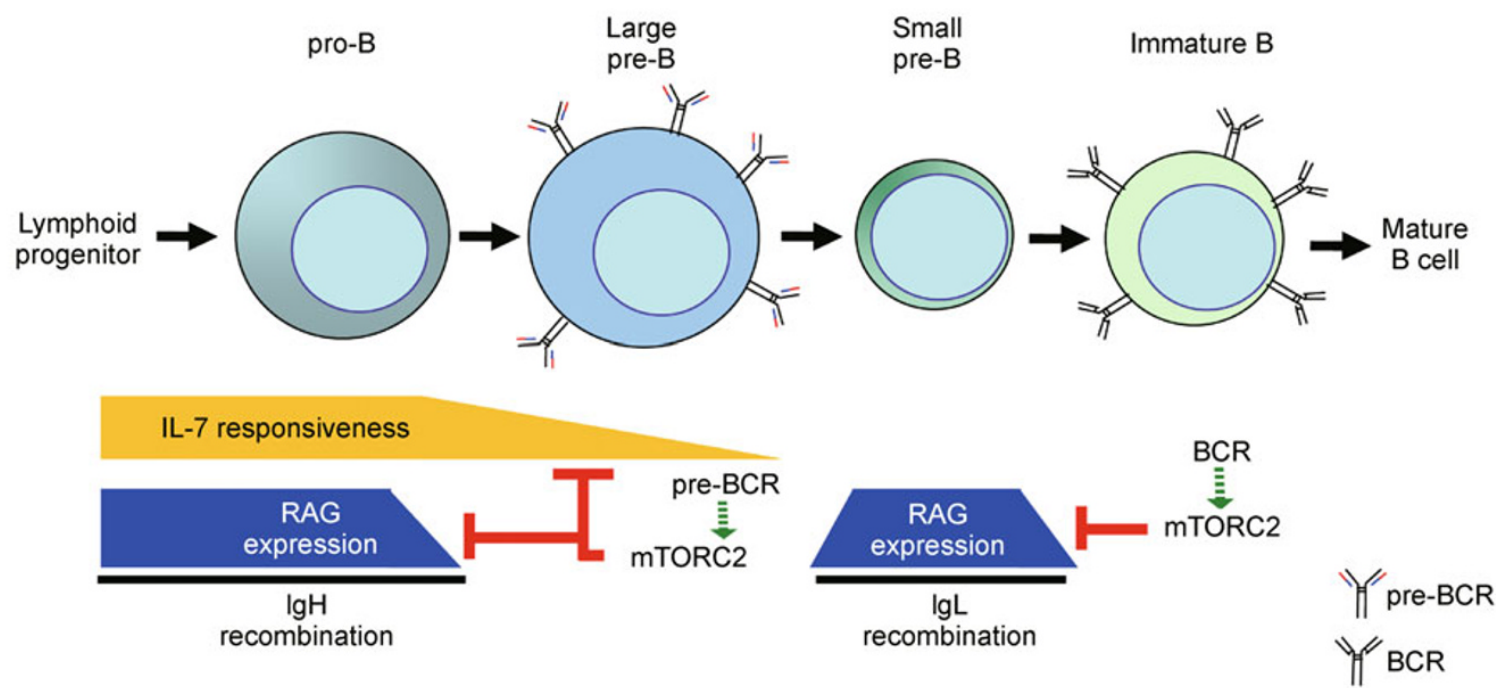

Figure 1. The role of $m$ TORC2 in B cell development in the bone marrow. Progenitor $B$ (pro-B) cells that differentiate from bone marrow common lymphoid progenitors are dependent on IL-7 for growth and cell viability. Pro-B cells that produce a functional IgH allele by somatic recombination will express a surface pre-BCR and differentiate into large precursor B (pre-B) cells. Mammalian TORC2 mediates pre-BCR signals to suppress RAG expression which inhibits further IgH gene recombination and suppresses IL-7 receptor expression to limit the IL-7 dependent growth, proliferation, and survival of pre-B cells. Down regulation of the pre-BCR expression facilitates the transition to the small pre-B cell stage and the initiation of $\mathrm{IgL}$ recombination. Production of a functional IgL allele results in expression of the BCR on immature B cells. Immature B cells that express a self reactive BCR may attempt additional IgL rearrangements to produce a new, potentially non-self reactive BCR. Expression of a non-self reactive BCR inhibits IgL recombination through a mechanism which is, in part, mediated by mTORC2 dependent suppression of RAG expression. Surface $\mathrm{BCR}$ expression is required for further $\mathrm{B}$ cell maturation and survival in the spleen.

that the Sin1/mTORC2 dependent signaling facilitates the down regulation of IL-7 receptor thereby promoting the generation of $\operatorname{lgM}^{+}$immature $B$ cells.

$\mathrm{PI} 3 \mathrm{~K}$ signaling plays a key role in maintaining peripheral $\mathrm{B}$ cell homeostasis. The survival of mature B cells is maintained by tonic signaling from the BCR plus signaling via the receptor of the tumor necrosis factor-like ligand BLyS (B-lymphocyte stimulator) (Kraus et al., 2004; Stadanlick et al., 2008; Srinivasan et al., 2009; Mackay et al., 2010). PI3K mediates the BCR and BLyS receptor generated signals to activate Akt (Patke et al., 2006; Baracho et al., 2011). Deficiencies in PI3K or Akt result in impaired B cell development and compromised B cell immune responses (Okkenhaug et al., 2002; Calamito et al., 2010; Ramadani et al., 2010). In addition, FoxO1 has emerged as a key target of PI3K-Akt signaling that regulates $B$ cell development, Ig gene recombination, Ig class switching and somatic hyper-mutation (Amin and Schlissel, 2008; Dengler et al., 2008; Herzog et al., 2008; Chen et al., 2010). Since Akt is downstream of mTORC2, it is reasonable to assume that some of the developmental and immunologic defects observed in $A k t 1^{-/-} \mathrm{Akt2}^{-/-} \mathrm{B}$ cells will also be observed in mTORC2 deficient B cells (Calamito et al., 2010). Therefore, mTORC2 may regulate mature $B$ cell survival, $B C R$ dependent $B$ cell proliferation and play a role in development of marginal zone and B-1 cells which are major contributors to T-cell independent B cell immunity against bacterial capsular and cell-wall polysaccharides.

\section{MAMMALIAN TORC2 REGULATES RAG EXPRESSION AND V(D)J RECOMBINATION IN B CELLS}

B cell development is completely dependent on the rearrangement of immunoglobulin genes by $\mathrm{V}(\mathrm{D}) \mathrm{J}$ recombination. In each developing B-cell, functional Ig genes are produced by the joining together of variable $(\mathrm{V})$, diversity $(\mathrm{D})$ and joining $(\mathrm{J})$ gene segments. $V(D) J$ recombination is a highly regulated process that occurs only in developing lymphoid cells in a lineage specific (B cells rearrange Ig genes; T cells rearrange TCR genes), stage specific (IgH genes recombine first followed by IgL gene recombination in B cells), and ordered (IgH D-J recombination occurs first followed by V-DJ recombination) manner (Schlissel and Stanhope-Baker, 1997; Schlissel, 2003; Chowdhury and Sen, 2004; Goldmit and Bergman, 2004). Each V, D and J gene segment is flanked by a conserved recombination signal sequence (RSS) that is recognized by the $V(D) J$ recombinase, encoded by the recombinase activating genes rag1 and rag2. RAG1 and RAG2 bind to two RSSs and introduce double strand DNA breaks that facilitate recombination of the gene 
sequences adjacent to the RSSs (Jung and Alt, 2004).

RAG expression is highly regulated during $B$ cell development to ensure that the $V(D) J$ recombinase activity is limited only to non-dividing cells that are actively undergoing lg gene rearrangement. Once a functional Ig gene is produced, RAG expression is down-regulated to prevent further $V(D) J$ recombination from occurring, ensuring that each $B$ cell only expresses a monoclonal Ig receptor. RAG expression is inhibited by signals initiated by expression of the pre-BCR ( $\mathrm{lgH}+$ surrogate light chain) or $\mathrm{BCR}(\mathrm{lgH}+\mathrm{IgL})$. PI3K and Akt are key downstream mediators of pre-BCR and $B C R$ signaling that negatively regulate RAG expression (Llorian et al., 2007; Verkoczy et al., 2007; Amin and Schlissel, 2008). In $B$ cells it was recently shown that Akt inhibits RAG expression by suppressing the transcriptional activity of FoxO1, which is a direct regulator of rag gene transcription (Amin and Schlissel, 2008; Dengler et al., 2008; Herzog et al., 2008, 2009).

Disruption of $\operatorname{Sin} 1$ in $B$ cells results in an abnormal elevation of RAG expression in developing bone marrow $B$ cells and peripheral splenic B cells (Lazorchak et al., 2010). Since mTORC2 mediates growth factor dependent Akt HM phosphorylation, we hypothesized that Akt was the principle mediator through which mTORC2 regulates RAG expression. Indeed, deletion of Akt2 but not Akt1 in progenitor B cells resulted in a similar increase in RAG expression as seen in Sin1 deficient B cells (Lazorchak et al., 2010). Furthermore, loss of either Akt2 or Sin1 severely impaired FoxO1 Thr24 phosphorylation resulting in an increase in total FoxO1 protein levels in progenitor $B$ cells. Finally, ectopic expression of human (h) Akt bearing an HM phosphomimetic S473D mutation suppressed RAG expression in $\operatorname{Sin} 1^{-/-}$B cells while expression of hAkt with an HM null S473A mutation had no effect on RAG expression in these cells (Lazorchak et al., 2010). These data strongly support a model where mTORC2 regulates RAG expression in $\mathrm{B}$ cells through an Akt2-FoxO1 dependent mechanism.

Since we observed increased rag1 and rag2 expression in developing $\operatorname{Sin}^{-1-}$ B cells, we hypothesized that RAG recombinase activity would be increased in these cells as well. Indeed, we found that $\operatorname{Sin} 1^{-/-}$B cells exhibited a significantly higher rate of RAG dependent recombination of a retrovirus containing an artificial $\mathrm{V}(\mathrm{D}) \mathrm{J}$ recombination substrate. Furthermore, we observed that immature $\operatorname{lgM}^{+} \operatorname{Sin} 1$ deficient $B$ cells show evidence of increased IgL receptor editing, implying that mTORC2 dependent signaling influences immunoglobulin gene $V(D) J$ recombination as well. Our data indicate that $\mathrm{mTORC} 2$ mediates pre-BCR signaling to facilitate $B$ cell differentiation and suppresses RAG expression when a functional pre-BCR or BCR is expressed. Based on our findings and those from other laboratories, we propose a model that depicts the growth factor independent and growth factor dependent functions of $\mathrm{mTORC} 2$ in pre-B cells as shown in Fig. 2.

\section{COULD MTOR INHIBITION PROMOTE B CELL TUMOR FORMATION?}

An important observation that emerged from our investigation of $\operatorname{Sin} 1^{-/-}$B cells was that mTORC2 inhibition permits actively dividing $B$ cells to express high levels of the RAG recombinase. Rag gene transcription is strongly suppressed in proliferating $B$ cells and RAG 2 protein degradation is linked to the cell cycle (Grawunder et al., 1995; Li et al., 1996; Zhang et al., 2011). These two mechanisms help to prevent RAG mediated double strand DNA breaks from occurring in dividing cells and limit the potential for mutation and tumor formation. Mammalian TORC2 couples signals that promote cell growth and proliferation to the regulation of RAG expression to ensure that recombinase activity is minimized in an actively dividing population of $B$ cells. The regulation of RAG expression by mTORC2 is not just limited to $B$ cells expressing a pre-BCR or BCR. Disruption of $\mathrm{MTORC} 2$ in pro$B$ cells which lack a functional $\mathrm{lgH}$ or $\mathrm{Abl}$ oncogene transformed pre-B leukemia cells also results in a substantial up-regulation of RAG expression. These observations suggest that cellular growth signals regulate RAG expression and $\mathrm{V}(\mathrm{D}) \mathrm{J}$ recombination through $\mathrm{mTOR}$.

RAG mediated double strand breaks are repaired by the non-homologous end-joining (NHEJ) DNA repair pathway. Developing $\mathrm{p} 53^{-/-}$pro-B cells with impaired NHEJ DNA repair frequently exhibit oncogenic, RAG dependent chromosome translocations involving the Ig genes (Zhu et al., 2002). Since mTORC2 inhibition simultaneously increases RAG expression in pro-B cells and enhances IL-7 dependent pro-B cell survival, it is possible that disrupting $\mathrm{mTORC} 2$ may contribute to progenitor B cell tumor formation. Surprisingly, mTORC2 is not required for the transformation, proliferation and survival of Abelson murine leukemia virus (v-Abl) or human p210 BCR-Abl oncogene dependent pre-B acute lymphoblastic leukemia (ALL) (Lazorchak et al., 2010) (AL and BS, unpublished data). This was a particularly unexpected finding since $\mathrm{Abl}$ oncogene dependent suppression of FoxO activity protects pre-B ALL cells from apoptosis (Kharas et al., 2004). It is possible that an alternative pathway such as STAT5, which signals downstream of IL-7R, v-Abl, and BCR-Abl, complements the mTORC2 deficiency and maintains cell viability.

Activation induced (cytidine) deaminase (AID) is a B cell specific DNA mutator which is essential for normal $B$ cell immunity. AID is highly expressed in activated B cells and permits Ig gene diversification by facilitating the formation of double strand DNA breaks in Ig switch regions that permit Ig class switch recombination and by generating mutations in the Ig genes which permit Ig affinity maturation. However, AID activity is not restricted to the Ig genes. AID acts widely across the genome to introduce DNA breaks which may occur near known B cell proto-oncogenes (Hasham et al., 2010; Staszewski et al., 2011; Yamane et al., 2011). FoxO1 is a 


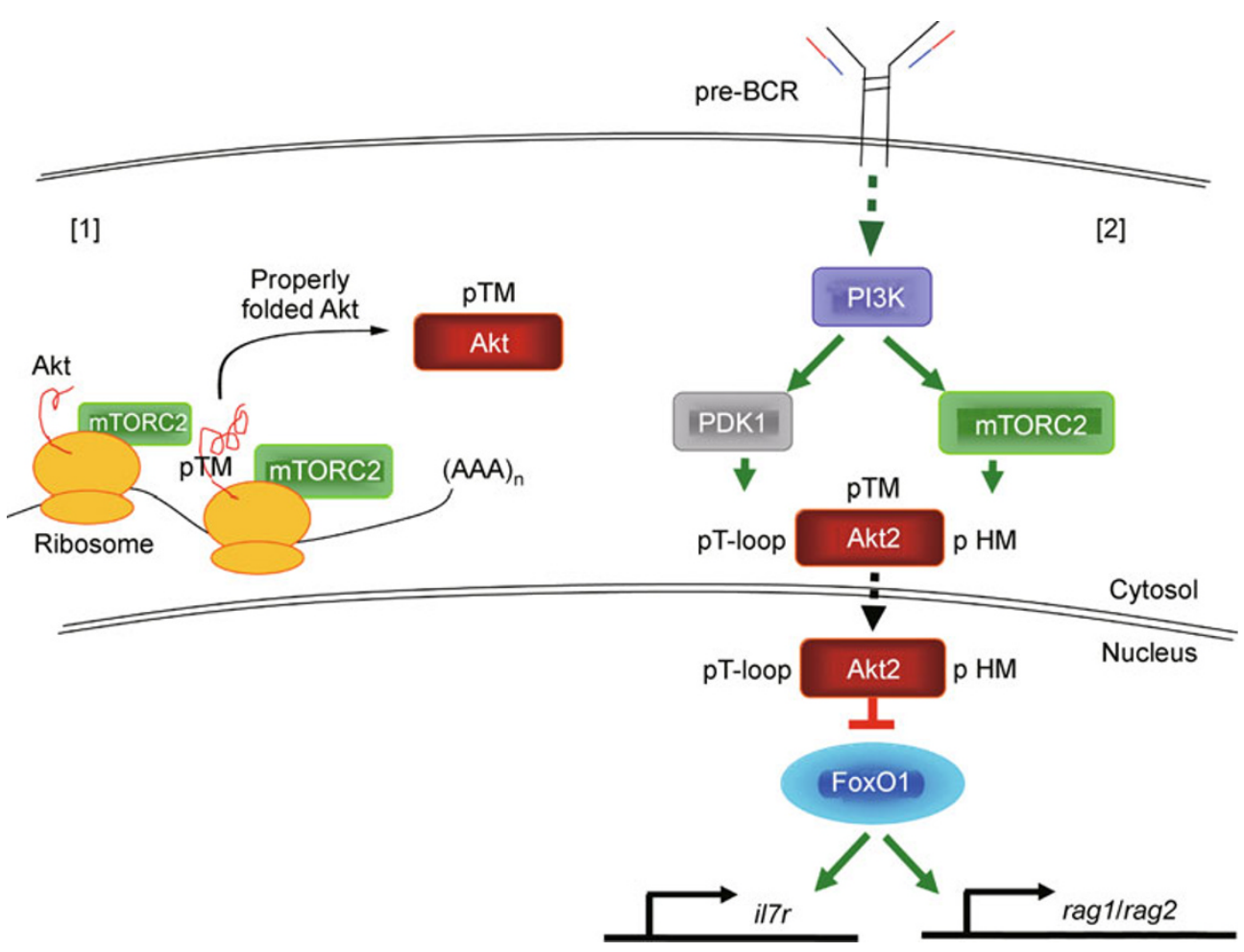

Figure 2. A model illustrating the growth factor independent [1] and growth factor dependent [2] functions of $m$ TORC2 in pre-B cells. [1] mTORC2 promotes the stability of maturation of newly synthesized Akt and classical (c)PKC polypeptides. In this example, we show that mTORC2, associated with ribosomes in a growth factor independent manner, phosphorylates the TM site of the Akt polypeptide. TM phosphorylation stabilizes the nascent Akt polypeptide and facilitates the maturation of the properly folded Akt protein. The chaperone protein Hsp90 may facilitate the proper maturation of Akt or cPKC and stabilize these proteins if TM phosphorylation is inhibited. [2] Expression of a functional pre-BCR signals to PI3K. PDK1 and mTORC2 then mediate the PI3K signals to phosphorylate Akt at the T-loop and HM sites, respectively. Activated Akt2 then phosphorylates FoxO1 in the nucleus resulting in the down regulation of FoxO1 transcriptional activity and reduced il7r and rag gene expression. Loss of mTORC2 function in developing B cells blocks Akt2 HM site phosphorylation and prevents the full activation of Akt2 resulting in insufficient inhibition of FoxO1. This leads to increased $i / 7 r$ and rag gene expression resulting in increased IL-7 dependent survival and increased recombinase activity, respectively, in developing $B$ cells

positive regulator of AID expression in B cells (Dengler et al., 2008). Since mTORC2 regulates FoxO1 activity in $B$ cells it is possible that inhibition of mTORC2 may induce AID expression. It is highly likely that inhibition of mTOR in B cells may create a situation where RAG and AID are co-expressed, and thus may significantly increase the risk for chromosomal translocation (Tsai et al., 2008; Wang et al., 2008; Wang et al., 2009). Further studies must be done to explore the role of mTOR in preserving B cell genome integrity and to determine if the use of mTOR inhibitors increases the risk of generating B cell tumors.

\section{INHIBITING MTORC2 DEPENDENT Akt TM PHOSPHORYLATION AND Hsp90 TO TREAT CANCER}

Constitutive activation of the Akt signaling pathway is a common feature of nearly all cancers. Akt promotes tumor cell growth, proliferation and survival so inhibition of the Akt signaling pathway is a logical target for cancer therapy. The discovery that mTORC2 directly regulates Akt raises the possibility that mTOR inhibitors may serve as useful inhibitors of Akt activity in cancers. Consistently, the rapamycin derivatives temsirolimus and everolimus are capable in inhibiting mTORC2 assembly and Akt S473 phosphorylation in human acute myelogenous leukemia (Zeng et al., 2007). Furthermore, the new generation of mTOR kinase inhibitors is capable of efficiently blocking mTORC2 dependent phosphorylation of Akt and shows anti-tumor effects (Feldman et al., 2009; Hoang et al., 2010; Janes et al., 2010). The rational of these therapeutic approaches is that inhibition of mTORC2 dependent Akt HM phosphorylation will sufficiently impair Akt signaling to inhibit tumor growth and promote tumor cell death. However, Akt lacking the HM phosphorylation is still partially functional and may still support tumor cell viability.

Loss of mTORC2 function also impairs Akt TM phosphorylation. We have shown that Akt TM phosphorylation is dependent on mTORC2 and is required to stabilize newly 
synthesized Akt. In cells lacking mTORC2, the chaperone Hsp90 prevents Akt degradation and sustains Akt expression. Therefore, we propose a novel therapeutic strategy based on the rational that inhibition of Hsp90 will significantly reduce the stability of Akt lacking TM phosphorylation and, as a consequence, inhibit Akt expression. We propose that the effectiveness of mTOR inhibitors can be significantly enhanced by combining their use with the Hsp90 inhibitor 17-AAG. Since mTORC2 dependent Akt TM phosphorylation is ubiquitous and independent of growth factor signaling, we believe this strategy of inhibiting Akt may be widely applicable to many cancers. Furthermore, we predict that Hsp90 inhibitors will synergize with mTOR inhibitors to promote tumor cell death in cancers that are resistant to either drug alone.

\section{CONCLUSION}

Our rapidly expanding understanding of mTOR signaling has provided new insights into the links between the regulation of cell metabolism and immunity. Rapamycin suppresses B cell immunity by inhibiting B cell growth and proliferation (Wicker et al., 1990). Since we observed that mTORC2 was inhibited in $B$ cells treated with $10 \mathrm{nmol} / \mathrm{L}$ rapamycin for greater than $24 \mathrm{~h}$ (Lazorchak et al., 2010), it is possible that the simultaneous inhibition of mTORC1 and mTORC2 by rapamycin contributed to $B$ cell immunosuppression observed in previous studies (Wicker et al., 1990). Therefore, the mechanism through which mTOR mediates antigen signals to control the metabolic changes that support blast cell growth and clonal expansion of $B$ cells during an immune response remains to be elucidated. Mammalian TOR is the principle growth regulator and sensor of nutrients and energy status in our cells. Cell growth control is associated with mTORC1; however it is likely that mTORC2 may have unique roles in regulating cell growth and metabolism as well. Our emerging understanding of mTORC2 signaling and its associated cellular functions have opened exciting new routes to expand our investigation of B cell immunity and provided novel therapeutic avenues to treat $B$ cell associated autoimmune diseases and cancer.

\section{ACKNOWLEDGEMENTS}

We thank Fan Zhang and Dou Liu of Dr. Bing Su's lab for the many insightful discussions that helped in the writing of this review. This work is supported in part by grant $\mathrm{Al} 063348(\mathrm{NIH})$ and PR093728 (DOD) (to B.S.). A.S.L. is a recipient of Brown-Cox Fellowship from Yale University and is currently a Leukemia \& Lymphoma Society fellow.

\section{ABBREVIATIONS}

AID, activation induced (cytidine) deaminase; BCR, B cell antigen receptor; $\mathrm{HM}$, hydrophobic motif, $\mathrm{IgH}$, immunoglobulin heavy chain; IgL, immunoglobulin light chain; mTORC2, mammalian target of rapamycin complex 2; PI3K, phosphoinositide 3-kinase; PIKK, PI3Krelated kinases; $V(D) J$ recombination, rearrangement of immunoglobulin genes segment of variable (V), diversity (D) and joining (J); TM, turn motif

\section{REFERENCES}

Amin, R.H., and Schlissel, M.S. (2008). Foxo1 directly regulates the transcription of recombination-activating genes during $B$ cell development. Nat Immunol 9, 613-622.

Baracho, G.V., Miletic, A.V., Omori, S.A., Cato, M.H., and Rickert, R. C. (2011). Emergence of the PI3-kinase pathway as a central modulator of normal and aberrant B cell differentiation. Curr Opin Immunol 23, 178-183.

Calamito, M., Juntilla, M.M., Thomas, M., Northrup, D.L., Rathmell, J., Birnbaum, M.J., Koretzky, G., and Allman, D. (2010). Akt1 and Akt2 promote peripheral B-cell maturation and survival. Blood 115, 4043-4050.

Chen, J., Limon, J.J., Blanc, C., Peng, S.L., and Fruman, D.A. (2010). Foxo1 regulates marginal zone B-cell development. Eur J Immunol 40, 1890-1896.

Chowdhury, D., and Sen, R. (2004). Regulation of immunoglobulin heavy-chain gene rearrangements. Immunol Rev 200, 182-196.

Dengler, H.S., Baracho, G.V., Omori, S.A., Bruckner, S., Arden, K.C., Castrillon, D.H., DePinho, R.A., and Rickert, R.C. (2008). Distinct functions for the transcription factor Foxo1 at various stages of $B$ cell differentiation. Nat Immunol 9, 1388-1398.

Facchinetti, V., Ouyang, W., Wei, H., Soto, N., Lazorchak, A., Gould, C., Lowry, C., Newton, A.C., Mao, Y., Miao, R.Q., et al. (2008b). The mammalian target of rapamycin complex 2 controls folding and stability of Akt and protein kinase C. EMBO J 27, 1932-1943.

Feldman, M.E., Apsel, B., Uotila, A., Loewith, R., Knight, Z.A., Ruggero, D., and Shokat, K.M. (2009). Active-site inhibitors of mTOR target rapamycin-resistant outputs of mTORC1 and mTORC2. PLoS Biol 7, e38.

Frias, M.A., Thoreen, C.C., Jaffe, J.D., Schroder, W., Sculley, T., Carr, S.A., and Sabatini, D.M. (2006). mSin1 is necessary for Akt/PKB phosphorylation, and its isoforms define three distinct mTORC2s. Curr Biol 16, 1865-1870.

Gingras, A.C., Raught, B., and Sonenberg, N. (2004). mTOR signaling to translation. Curr Top Microbiol Immunol 279, 169-197.

Goldmit, M., and Bergman, Y. (2004). Monoallelic gene expression: a repertoire of recurrent themes. Immunol Rev 200, 197-214.

Grawunder, U., Leu, T.M., Schatz, D.G., Werner, A., Rolink, A.G., Melchers, F., and Winkler, T.H. (1995). Down-regulation of RAG1 and RAG2 gene expression in preB cells after functional immunoglobulin heavy chain rearrangement. Immunity 3 , 601-608.

Guertin, D.A., and Sabatini, D.M. (2009). The pharmacology of mTOR inhibition. Sci Signal 2, pe24.

Guertin, D.A., Stevens, D.M., Thoreen, C.C., Burds, A.A., Kalaany, N. Y., Moffat, J., Brown, M., Fitzgerald, K.J., and Sabatini, D.M. (2006). Ablation in mice of the mTORC components raptor, rictor, or $\mathrm{mLST} 8$ reveals that $\mathrm{mTORC2}$ is required for signaling to AktFOXO and PKCalpha, but not S6K1. Dev Cell 11, 859-871.

Harris, T.E., and Lawrence, J.C. Jr. (2003). TOR signaling. Sci STKE 2003, re15.

Hasham, M.G., Donghia, N.M., Coffey, E., Maynard, J., Snow, K.J., Ames, J., Wilpan, R.Y., He, Y., King, B.L., and Mills, K.D. (2010). 
Widespread genomic breaks generated by activation-induced cytidine deaminase are prevented by homologous recombination. Nat Immunol 11, 820-826.

Herzog, S., Hug, E., Meixlsperger, S., Paik, J.H., DePinho, R.A., Reth, M., and Jumaa, H. (2008). SLP-65 regulates immunoglobulin light chain gene recombination through the PI(3)K-PKB-Foxo pathway. Nat Immunol 9, 623-631.

Herzog, S., Reth, M., and Jumaa, H. (2009). Regulation of B-cell proliferation and differentiation by pre-B-cell receptor signalling. Nat Rev Immunol 9, 195-205.

Hietakangas, V., and Cohen, S.M. (2007). Re-evaluating AKT regulation: role of TOR complex 2 in tissue growth. Genes Dev 21, 632-637.

Hoang, B., Frost, P., Shi, Y., Belanger, E., Benavides, A., Pezeshkpour, G., Cappia, S., Guglielmelli, T., Gera, J., and Lichtenstein, A. (2010). Targeting TORC2 in multiple myeloma with a new mTOR kinase inhibitor. Blood 116, 4560-4568.

Ikenoue, T., Inoki, K., Yang, Q., Zhou, X., and Guan, K.L. (2008). Essential function of TORC2 in PKC and Akt turn motif phosphorylation, maturation and signalling. EMBO J 27, 1919-1931.

Jacinto, E., Facchinetti, V., Liu, D., Soto, N., Wei, S., Jung, S.Y., Huang, Q., Qin, J., and Su, B. (2006). SIN1/MIP1 maintains rictormTOR complex integrity and regulates Akt phosphorylation and substrate specificity. Cell 127, 125-137.

Janes, M.R., Limon, J.J., So, L., Chen, J., Lim, R.J., Chavez, M.A., Vu, C., Lilly, M.B., Mallya, S., Ong, S.T., et al. (2010). Effective and selective targeting of leukemia cells using a TORC1/2 kinase inhibitor. Nat Med 16, 205-213.

Jung, D., and Alt, F.W. (2004). Unraveling V(D)J recombination; insights into gene regulation. Cell 116, 299-311.

Kharas, M.G., Deane, J.A., Wong, S., O'Bosky, K.R., Rosenberg, N., Witte, O.N., and Fruman, D.A. (2004). Phosphoinositide 3-kinase signaling is essential for $A B L$ oncogene-mediated transformation of B-lineage cells. Blood 103, 4268-4275.

Kraus, M., Alimzhanov, M.B., Rajewsky, N., and Rajewsky, K. (2004). Survival of resting mature $B$ lymphocytes depends on BCR signaling via the Igalpha/beta heterodimer. Cell 117, 787-800.

Lazorchak, A.S., Liu, D., Facchinetti, V., Di Lorenzo, A., Sessa, W.C., Schatz, D.G., and Su, B. (2010). Sin1-mTORC2 suppresses rag and il7r gene expression through Akt2 in B cells. Mol Cell 39, $433-443$.

Li, Z., Dordai, D.I., Lee, J., and Desiderio, S. (1996). A conserved degradation signal regulates RAG-2 accumulation during cell division and links $\mathrm{V}(\mathrm{D}) \mathrm{J}$ recombination to the cell cycle. Immunity 5 , 575-589.

Llorian, M., Stamataki, Z., Hill, S., Turner, M., and Mårtensson, I.L. (2007). The PI3K p110delta is required for down-regulation of RAG expression in immature B cells. J Immunol 178, 1981-1985.

Mackay, F., Figgett, W.A., Saulep, D., Lepage, M., and Hibbs, M.L. (2010). B-cell stage and context-dependent requirements for survival signals from BAFF and the B-cell receptor. Immunol Rev 237, 205-225.

Malin, S., McManus, S., and Busslinger, M. (2010). STAT5 in B cell development and leukemia. Curr Opin Immunol 22, 168-176.

Manning, G., Whyte, D.B., Martinez, R., Hunter, T., and Sudarsanam, S. (2002). The protein kinase complement of the human genome. Science 298, 1912-1934.
Oh, W.J., Wu, C.C., Kim, S.J., Facchinetti, V., Julien, L.A., Finlan, M., Roux, P.P., Su, B., and Jacinto, E. (2010). mTORC2 can associate with ribosomes to promote cotranslational phosphorylation and stability of nascent Akt polypeptide. EMBO J 29, 3939-3951.

Okkenhaug, K., Bilancio, A., Farjot, G., Priddle, H., Sancho, S., Peskett, E., Pearce, W., Meek, S.E., Salpekar, A., Waterfield, M.D., et al. (2002). Impaired B and T cell antigen receptor signaling in p110delta PI 3-kinase mutant mice. Science 297, 1031-1034.

Patke, A., Mecklenbräuker, I., Erdjument-Bromage, H., Tempst, P., and Tarakhovsky, A. (2006). BAFF controls B cell metabolic fitness through a PKC beta- and Akt-dependent mechanism. J Exp Med 203, 2551-2562.

Ramadani, F., Bolland, D.J., Garcon, F., Emery, J.L., Vanhaesebroeck, B., Corcoran, A.E., and Okkenhaug, K. (2010). The PI3K isoforms p110alpha and p110delta are essential for pre-B cell receptor signaling and $B$ cell development. [Electronic Resource] Sci Signal 3, ra60.

Sarbassov, D.D., Ali, S.M., Sengupta, S., Sheen, J.H., Hsu, P.P., Bagley, A.F., Markhard, A.L., and Sabatini, D.M. (2006). Prolonged rapamycin treatment inhibits $m$ TORC2 assembly and Akt/PKB. Mol Cell 22, 159-168.

Sarbassov, D.D., Guertin, D.A., Ali, S.M., and Sabatini, D.M. (2005). Phosphorylation and regulation of Akt/PKB by the rictor-mTOR complex. Science 307, 1098-1101.

Schlissel, M.S. (2003). Regulating antigen-receptor gene assembly. Nat Rev Immunol 3, 890-899.

Schlissel, M.S., and Stanhope-Baker, P. (1997). Accessibility and the developmental regulation of $\mathrm{V}(\mathrm{D}) \mathrm{J}$ recombination. Semin Immunol 9, 161-170.

Srinivasan, L., Sasaki, Y., Calado, D.P., Zhang, B., Paik, J.H., DePinho, R.A., Kutok, J.L., Kearney, J.F., Otipoby, K.L., and Rajewsky, K. (2009). PI3 kinase signals BCR-dependent mature B cell survival. Cell 139, 573-586.

Stadanlick, J.E., Kaileh, M., Karnell, F.G., Scholz, J.L., Miller, J.P., Quinn, W.J. 3rd, Brezski, R.J., Treml, L.S., Jordan, K.A., Monroe, J. G., et al. (2008). Tonic B cell antigen receptor signals supply an NFkappaB substrate for prosurvival BLyS signaling. Nat Immunol 9, 1379-1387.

Staszewski, O., Baker, R.E., Ucher, A.J., Martier, R., Stavnezer, J., and Guikema, J.E. (2011). Activation-induced cytidine deaminase induces reproducible DNA breaks at many non-Ig Loci in activated B cells. Mol Cell 41, 232-242.

Tsai, A.G., Lu, H., Raghavan, S.C., Muschen, M., Hsieh, C.L., and Lieber, M.R. (2008). Human chromosomal translocations at CpG sites and a theoretical basis for their lineage and stage specificity. Cell 135, 1130-1142.

Verkoczy, L., Duong, B., Skog, P., Aït-Azzouzene, D., Puri, K., Vela, J. L., and Nemazee, D. (2007). Basal B cell receptor-directed phosphatidylinositol 3-kinase signaling turns off RAGs and promotes B cell-positive selection. J Immunol 178, 6332-6341.

Wang, J.H., Alt, F.W., Gostissa, M., Datta, A., Murphy, M., Alimzhanov, M.B., Coakley, K.M., Rajewsky, K., Manis, J.P., and Yan, C.T. (2008). Oncogenic transformation in the absence of Xrcc4 targets peripheral $\mathrm{B}$ cells that have undergone editing and switching. J Exp Med 205, 3079-3090.

Wang, J.H., Gostissa, M., Yan, C.T., Goff, P., Hickernell, T., Hansen, E., Difilippantonio, S., Wesemann, D.R., Zarrin, A.A., Rajewsky, K., et al. (2009). Mechanisms promoting translocations in editing and 
switching peripheral B cells. Nature 460, 231-236.

Wicker, L.S., Boltz, R.C. Jr, Matt, V., Nichols, E.A., Peterson, L.B., and Sigal, N.H. (1990). Suppression of B cell activation by cyclosporin A, FK506 and rapamycin. Eur J Immunol 20, 2277-2283.

Wu, Y.-T., Ouyang, W., Lazorchak, A.S., Liu, D., Shen, H.-M., and Su, B. (2011). mTOR Complex 2 Targets Akt for Proteasomal Degradation via Phosphorylation at the Hydrophobic Motif.J Biol Chem 286, 14190-14198.

Wullschleger, S., Loewith, R., and Hall, M.N. (2006a). TOR signaling in growth and metabolism. Cell 124, 471-484.

Yamane, A., Resch, W., Kuo, N., Kuchen, S., Li, Z., Sun, H.W., Robbiani, D.F., McBride, K., Nussenzweig, M.C., and Casellas, R. (2011). Deep-sequencing identification of the genomic targets of the cytidine deaminase AID and its cofactor RPA in B lymphocytes.
Nat Immunol 12, 62-69.

Zeng, Z., Sarbassov, D.D., Samudio, I.J., Yee, K.W.L., Munsell, M.F., Ellen Jackson, C., Giles, F.J., Sabatini, D.M., Andreeff, M., and Konopleva, M. (2007). Rapamycin derivatives reduce mTORC2 signaling and inhibit AKT activation in AML Blood 109, 3509 3512.

Zhang, L., Reynolds, T.L., Shan, X., and Desiderio, S. (2011). Coupling of $V(D) J$ recombination to the cell cycle suppresses genomic instability and lymphoid tumorigenesis. Immunity 34 , 163-174.

Zhu, C., Mills, K.D., Ferguson, D.O., Lee, C., Manis, J., Fleming, J., Gao, Y., Morton, C.C., and Alt, F.W. (2002). Unrepaired DNA breaks in p53-deficient cells lead to oncogenic gene amplification subsequent to translocations. Cell 109, 811-821. 